\title{
ELECTROSPUN NANOFIBERS REINFORCED Aluminium Matrix Composites, A Trial To IMPROVE THE MECHANICAL PROPERTIES
}

\author{
Hany S. Abdo ${ }^{1,2,3, *}$, Khalil Abdelrazek Khalil ${ }^{2,4, *}$, Magdy M. El-Rayes ${ }^{5}$, \\ Wagih W. Marzouk ${ }^{3}$, A.M. Hashem ${ }^{6}$ and G.T. Abdel-Jaber ${ }^{6}$ \\ ${ }^{1}$ Center of Excellence for Research in Engineering Materials (CEREM), \\ Deanship of scientific research, King Saud University, P.O. Box 800, \\ Al-Riyadh 11421, Saudi Arabia. \\ ${ }^{2}$ Mechanical Design and Materials Department, Faculty of Energy \\ Engineering, Aswan University, Aswan 81521, Egypt. \\ ${ }^{3}$ Production Engineering and Design Department, Faculty of Engineering, \\ Minia Universities, Minia 61111, Egypt. \\ ${ }^{4}$ Department of Mechanical Engineering, College of Engineering, \\ University of Sharjah, P.O. Box 27272, Sharjah, UAE \\ ${ }^{5}$ Mechanical Engineering Department, College of Engineering, King Saud \\ University, P O Box 800, Riyadh 11421, Saudi Arabia. \\ ${ }^{6}$ Department of Engineering Materials and Mechanical Design, Faculty of \\ Engineering, South Valley of University, Qena 83523, Egypt.
}

\begin{abstract}
A comparison between TiO2 nanofibers and carbon nanofibers as fibers reinforced metal matrix composites with respect to mechanical properties improvements have been made in this paper. Al and Mg have been chosen as metal matrices. The used carbon and ceramic nanofibers (Titanium Oxide) were successfully synthesized using electrospinning technique. Various weight percentage of calcined electrospun TiO2 and carbon nanofibers (1, 3, 5 and 10\%) were mixed with metal matrix and fabricated by route of powder metallurgy using High Frequency Induction heat Sintering (HFIHS). Mechanical properties of the sintered composites have been investigated. The manufactured pellets were tested for compression test, hardness and microstructures by the field emission scanning electron microscopes (FESEM), which reveals the homogeneous distribution of nanofibers in the Al/Mg matrices. In addition, energy-dispersive X-ray spectroscopy (EDS) was employed to obtain the chemical analysis of each composite. The result shows that, the ultimate compressive strength increased to $415 \mathrm{MPa}$ at 5\% TiO2, which is $13.5 \%$ more than the pure Al. The hardness increased up to $64 \%$ in case of using the ceramic nanofibers as reinforcement. While using CNFs as reinforcement to the Al matrix deteriorates the mechanical properties.
\end{abstract}

\section{KEYWORDS:}

Aluminium Matrix; TiO2 Nanofibers; Carbon Nanofibers; Mechanical Properties

DOI:10.14810/ijamse.2018.7201 
International Journal of Advances in Materials Science and Engineering (IJAMSE) Vol.7, No.2, April 2018

\section{INTRODUCTION}

Metal matrix composites (MMCs) have been used in engineering applications in different ways because of their mechanical and physical properties [1-5]. In the previous ten years, aluminum matrix composites (AMCs) are used in hi-tech purposeful and structural applications such as automotive, aerospace and defence also as in sports and light industries [6, 7]. AMCs indicate to the category of light weight excessive efficiency Al centrical systems. Reinforcement in AMCs would be in the type of platelets, tubes, particulates, or fibres, in volume fractions starting from a few percentage up to 65\% [7]. The mechanical properties of AMCs can be custom fitted to the requests of various modern applications by playing with the reinforcement combinations and the preparing technique.

In traditional MMCs, ceramics, like $\mathrm{SiC}$ or $\mathrm{Al} 2 \mathrm{O} 3$, in the type of fibers, flakes or particulates are the most commonly used as reinforcements [6-9]. Nonetheless, the interference between the metallic matrix and the ceramic reinforcements are generally not perfect, which produce incredibly porous composites with less mechanical properties and higher corrosion sensibility [10]. As a way to resolve this drawback, metal-glasses had been proposed as a novel form of reinforcement in metal matrices composites [11-17]. The mechanical properties of aluminium composites are efficiently improved in case of using nano-fibers as a reinforcement. Accordingly, the high surface to volume ratio of nanofibers effectively enhance the strength and stiffness of $\mathrm{Al}$ composites compared to micro-fibers due to the good interface between the ceramic reinforcement (nano-fibers) and the metal matrix.

This work is mainly concerned with the evaluation of light-metal nanocomposites strength. The main objective of the current work is to studying the effect of adding two kind of nanofibers, $\mathrm{TiO} 2$ and $\mathrm{CNF}$ [in various contents ranging from 1:10 wt.\%] on the mechanical properties of light metal matrix, namely; Aluminium. In order to understand the trends observed in the properties of nanofiber reinforced, a comparison between both kinds of nanofibers as a reinforcement for metal matrix composites with respect to mechanical properties improvements have been performed.

Another objective from this study is to introduce a new nanocomposite material by using nanofiber as reinforcement and to improving the mechanical properties of the light metal matrix.

The study also focuses on the relationships between effective properties and properties of constituents (metal matrix and reinforcement), weight fraction of components, shape and arrangement of reinforcement, and the interaction between matrix and reinforcement.

\section{METHOdOLOGY AND EXPERIMENTAL PROCEDURES}

\subsection{METHODOLOGY}

To achieve our objective, the methodologies are as follows:

-Electrospinning of ceramic nanofibers,

- Calcinations of obtained nanofibers, to convert it into ceramic/carbon nanofibers,

-Use the ceramic/carbon nanofibers as reinforcement for Aluminium matrix,

- Sintering that nanocomposites by high-frequency induction heat sintering furnace HFIHS

with different compositions and temperatures 
International Journal of Advances in Materials Science and Engineering (IJAMSE) Vol.7, No.2, April 2018

- Characterizing the sintered pallets (SEM, XRD, ...etc),

-Studying the mechanical properties for the reinforced metal matrix nanocomposites.

\subsection{MATERIAls}

In this study, Titanium isopropoxide (C12 H28 O4 Ti), PVP (Mw = 1,300,000), Dimethylformamide (DMF) and Polyacrylonitrile (PAN) were obtained from Sigma- Aldrich, USA, and Ethanol, Acetic Acid, Aluminium Fine Powder was obtained from different sources as presented in table 1. All these chemicals and solvents were used as received without further purification.

Table 1: Compounds, Formula, purity and sources used for all experimental work

\begin{tabular}{|c|c|c|c|c|}
\hline $\begin{array}{c}\text { Materials or } \\
\text { Chemicals }\end{array}$ & $\begin{array}{c}\text { Linear } \\
\text { Formula }\end{array}$ & $\begin{array}{c}\mathrm{Mw} \\
(\mathrm{g} / \mathrm{mol})\end{array}$ & $\begin{array}{c}\text { Purit } \\
(\%)\end{array}$ & Source \\
\hline Titanium isopropoxide & $\mathrm{C}_{12} \mathrm{H}_{28} \mathrm{O}_{4} \mathrm{Ti}$ & 284.22 & 99.999 & Sigma-Aldrich \\
\hline Polyacrylonitrile (PAN) & $\mathrm{C}_{3} \mathrm{H}_{3} \mathrm{~N}$ & 150,000 & --- & Sigma-Aldrich \\
\hline Ethanol Absolute & $\mathrm{H}_{3} \mathrm{CCH}_{2} \mathrm{OH}$ & 46.07 & 96 & AVONCHEM \\
\hline $\begin{array}{c}\text { Dimethylformamide } \\
\text { (DMF) }\end{array}$ & $\mathrm{C}_{3} \mathrm{H}_{7} \mathrm{NO}$ & 73.09 & 99.8 & Sigma-Aldrich \\
\hline Acetic Acid Glacial & $\mathrm{CH}_{3 \mathrm{COOH}}$ & 1.05 & 99.7 & Qualikems, UK \\
\hline $\begin{array}{c}\text { Polyvinylpyrrolidone } \\
\text { (PVP) }\end{array}$ & $\left(\mathrm{C}_{6} \mathrm{H}_{9} \mathrm{NO}\right)_{n}$ & $\begin{array}{c}1,300,00 \\
0\end{array}$ & 95 & Sigma-Aldrich \\
\hline Aluminum Fine Powder & $\mathrm{Al}$ & 26.98 & 99 & Merck, Germany \\
\hline
\end{tabular}

\subsection{PRePARATION OF THE ELECTROSPUN NANOFIBER}

\subsubsection{TiO2 / PVP Solution}

In this step, titanium dioxide was prepared via sol-gel by adding $4.5 \mathrm{gm}$ of $\mathrm{Ti}(\mathrm{IV})$-isopropoxide $(\mathrm{C} 12 \mathrm{H} 28 \mathrm{O} 4 \mathrm{Ti})$, and $9 \mathrm{ml}$ of acetic acid as a solution to gelation containing $30 \mathrm{gm}$ of ethanol and 1.5 gm of polyvinylpyrrolidone (PVP, Aldrich, Mw 1,300,000). The mixture was vigorously stirred at room temperature for two hours to obtain 45 grams of a homogeneous viscous solution.

\subsubsection{Pan / Dmf Solution}

Polyacrylonitrile (PAN) (Mw 150,000) $7 \mathrm{wt} \%$ solution was prepared in N,N-dimethyformamide (DMF) with vigorous stirring for at least 2 hours to obtain a transparent polymer solution.

\subsubsection{Electrospinning Device}

A schematic diagram of the used electrospinning device used for producing polymer nanofibers is shown in Fig. (1). In a typical electrospinning setup, a high-voltage source is connected to a 
International Journal of Advances in Materials Science and Engineering (IJAMSE) Vol.7, No.2, April 2018

metallic needle, which is attached to a solution reservoir (syringe). The needle has a relatively small orifice that concentrates the electric charge density on a small pendant drop of solution.

There are basically three components to fulfil the process: a high voltage supplier, a syringe with needle of small diameter, and a collecting drum. In the electrospinning process a high voltage $(20 \mathrm{kV})$ is used to create an electrically charged jet of polymer solution. Before reaching the collecting drum, the solution jet evaporates or solidifies, and is collected as an interconnected mat of small fibers.

One electrode is placed into the spinning solution/needle and the other attached to the drum collector. In most cases, the collector is simply grounded, as indicated in Fig. (1). The electric field is affects the end of the needle that contains the solution fluid held by its surface tension

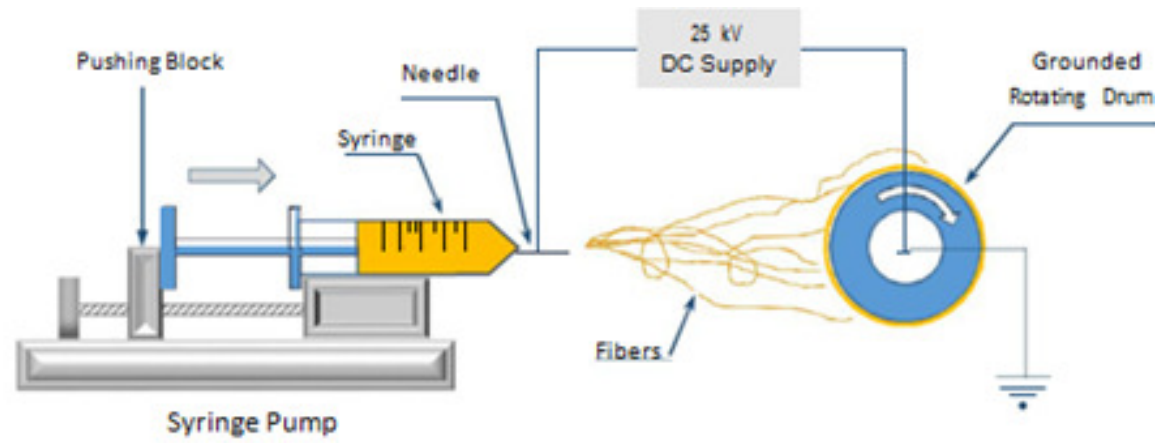

Figure1:Schematic Layout For The Electrospinning Process

\subsubsection{Calcination process}

Calcination is the process in which the nanofiber burned in air or inert atmosphere to produce CNF or metal-oxide nanofiber respectively. Usually it performed at temperatures above the thermaldecompositiontemperatureand below the melting point. In this study, tube furnace was used to perform calcination (CARBOLITE Type $3216 \mathrm{CC}$ up to $1600{ }^{\circ} \mathrm{C}$ ).

TiO2 nanofiber was calcined at $600{ }^{\circ} \mathrm{C}$ on air for $3 \mathrm{hrs}$. with heating rate of $10{ }^{\circ} \mathrm{C} / \mathrm{min}$, while PAN nanofibers mat were stabilized on air atmosphere at $270 \circ \mathrm{C}$ for $2 \mathrm{hrs}$ (with heating rate of $2{ }^{\circ} \mathrm{C} / \mathrm{min}$ ) followed by carbonization at $1000{ }^{\circ} \mathrm{C}$ for $1 \mathrm{hr}$ (with heating rate of $4{ }^{\circ} \mathrm{C} / \mathrm{min}$ ) on nitrogen atmosphere to produce carbon nanofiber (CNF).

\subsection{PREPARATION OF THE COMPOSITE POWDER}

In order to mix the produced ceramic and carbon nanofibers with Aluminium matrix we used high-energy ball milling technique (HEBM). Desktop 220V High Energy Vibratory Ball Mill with $80 \mathrm{ml}$ Jar from Across International Company, USA, was used in this study.

Aluminium Fine Powder (Al) was first de-agglomerated in the HEBM for 1 hour then TiO2 Ceramic Nanofibers and Carbon Nanofibers were added separately to the slurry for a certain time as mentioned in table 2 just for mixing. The following table summarize the different samplesandconcentrationused: 


\begin{tabular}{|c|c|c|c|}
\hline Base matrix & Reinforcement & $\begin{array}{c}\text { Reinforcement } \\
\text { percentage \% }\end{array}$ & Mixing time \\
\hline \multirow{2}{*}{$\begin{array}{c}\text { Aluminum Fine } \\
\text { Powder (Al) }\end{array}$} & TiO: Ceramic Nanofibers & \multirow{2}{*}{$1,3,5$ and 10} & 15 min \\
\cline { 2 - 2 } & Carbon Nanofibers & & 12 min \\
\hline
\end{tabular}

Table2:Samples Composition and milling time

\subsection{High FreQuency Induction Heat Sintering Procedure}

The composite powders were densified by using HFIHS process (HF, ELTek CO., Korea). $5 \mathrm{~g}$ of powder was putted into a graphite mold of $10 \mathrm{~mm}$ diameter. The sintering process was done under $40 \mathrm{MPa}$ pressure at temperature of $580^{\circ} \mathrm{C}$, for $5 \mathrm{~min}$. The compaction and sintering processes were done simultaneously at vacuum level of $2 \times 10-3$ Torr to prevent the oxida on of the surface of the composites. The sintered specimens were finally kept to cool down to reach room temperature. The heating rate from room temperature to $580^{\circ} \mathrm{C}$ was $250^{\circ} \mathrm{C} / \mathrm{min}$ with a holding time of $5 \mathrm{~min}$ in order to prevent the grain growth of the composite particles.

\subsection{Characterization}

The density of the samples was measured using Archimedes' principle using (DAHOMETER, DH 300L). Phase composition of the composites was analyzed by X-ray diffraction system (D-8 Discover, Bruker, Germany) and using CuKamonochromatic radiation. The microstructures and chemical composition of polished and thermal etched surfaces were characterized by fieldemission scanning electron microscope (FE-SEM) (JEOL; JSM7600F) equipped with energy dispersive X-ray spectroscopy (EDS). The hardness test was carried out using a Vickers microhardness tester (Buehler-micro-met 5114, Akashi Corporation, Japan) under an applied load of $500 \mathrm{~g}$ with an indentation time for $10 \mathrm{~s}$. The density and hardness reported in this work are the average values of six testing result

\subsection{COMPRESSION TEST}

In accordance with ASTM:E9-89a, the samples were determined at ambient temperature, using INSTRON testing machine with a strain rate of $8^{*} 10^{-5} \mathrm{~s} 1$. The test specimens of $10 \mathrm{~mm}$ diameter and length to diameter ratio $\mathrm{L} / \mathrm{d} \sim 1$ were used. For each composition, 3 samples were tested to ensure repeatable values.

\section{RESULTS AND DISCUSSION}

\subsection{SYNTHESIS AND MICROSTRUCTURE}

Fig. 2 (b) shows the SEM images of the $\mathrm{TiO} 2$ nanofibers (5wt\% Titanium Ispropoxide) after calcination process at $600{ }^{\circ} \mathrm{C}$ for three hours in air with different magnifications. It can be seen from this figure that nanofibers was partly twisted and arcuate. The diameters of nanofibers after calcination almost the same as before, no significant difference as shown in Fig.2(a) 

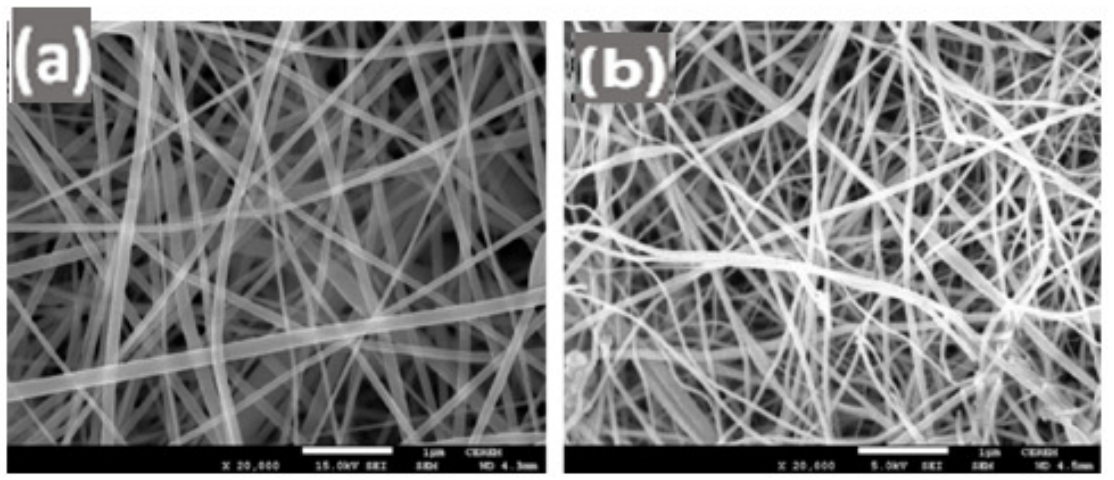

Figure 2: SEM images for $\mathrm{TiO}_{2}$ nanofiber mat (a) before and (b) after calcination

As shown in Fig. 3 (a), the approximate diameters of PAN nanofibers were $400 \mathrm{~nm}$. It looks homogeneous and uniform without beads or beaded nanofibers. The only difference in morphologies between the fiber bundles before and after calcination is the fiber diameter, which is reduced by a few nanometers as shown in Fig. 3 (b).
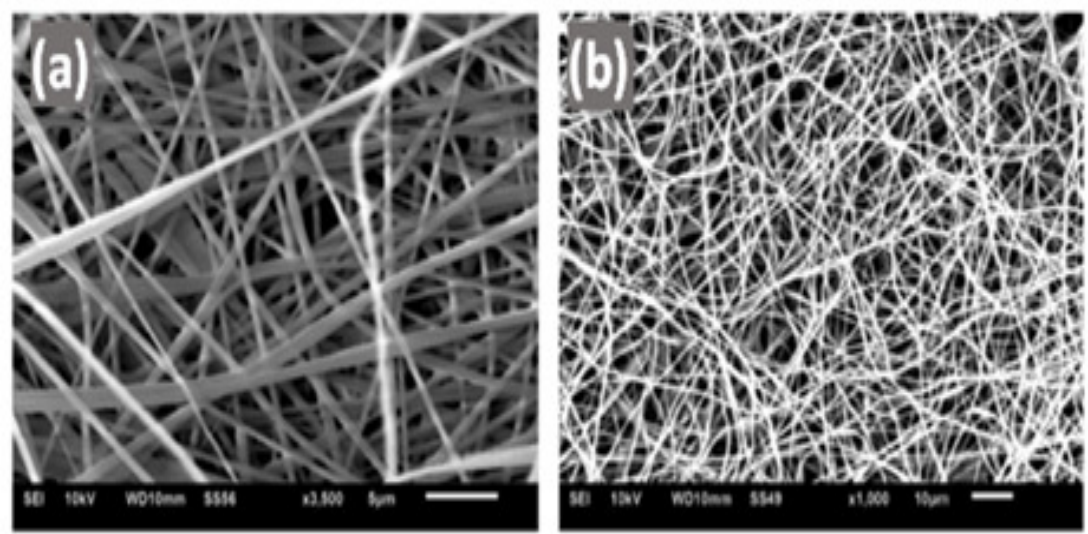

Figure 3:SEM Micrographs for PAN nano fiber (a)before and (b)CNF calcination

Fabrication of $\mathrm{Al} / \mathrm{TiO}_{2}$ and $\mathrm{Al} / \mathrm{CNF}$ nanocomposites were successfully completed by using powder metallurgy technique followed by high frequency induction heat sintering process.

Fig. 4 showed $\mathrm{TiO} 2$ nanofibers and $\mathrm{CNFs}$ (seen as light gray phase) were longitudinal in shape and homogeneously distributed in $\mathrm{Al}$ powder. It also shows how the mixing and embedding of nanofibers into powder to form composite. 
International Journal of Advances in Materials Science and Engineering (IJAMSE) Vol.7, No.2, April 2018
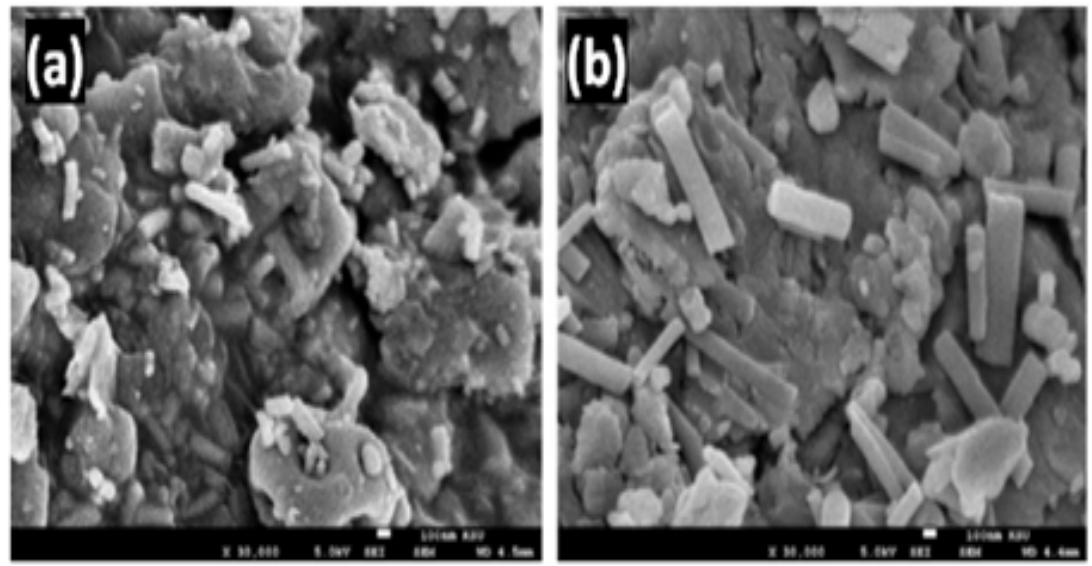

Figure 4: SEM images for (a) $\mathrm{Al} / \mathrm{TiO}_{2}$ (b) $\mathrm{Al} / \mathrm{CNF}$

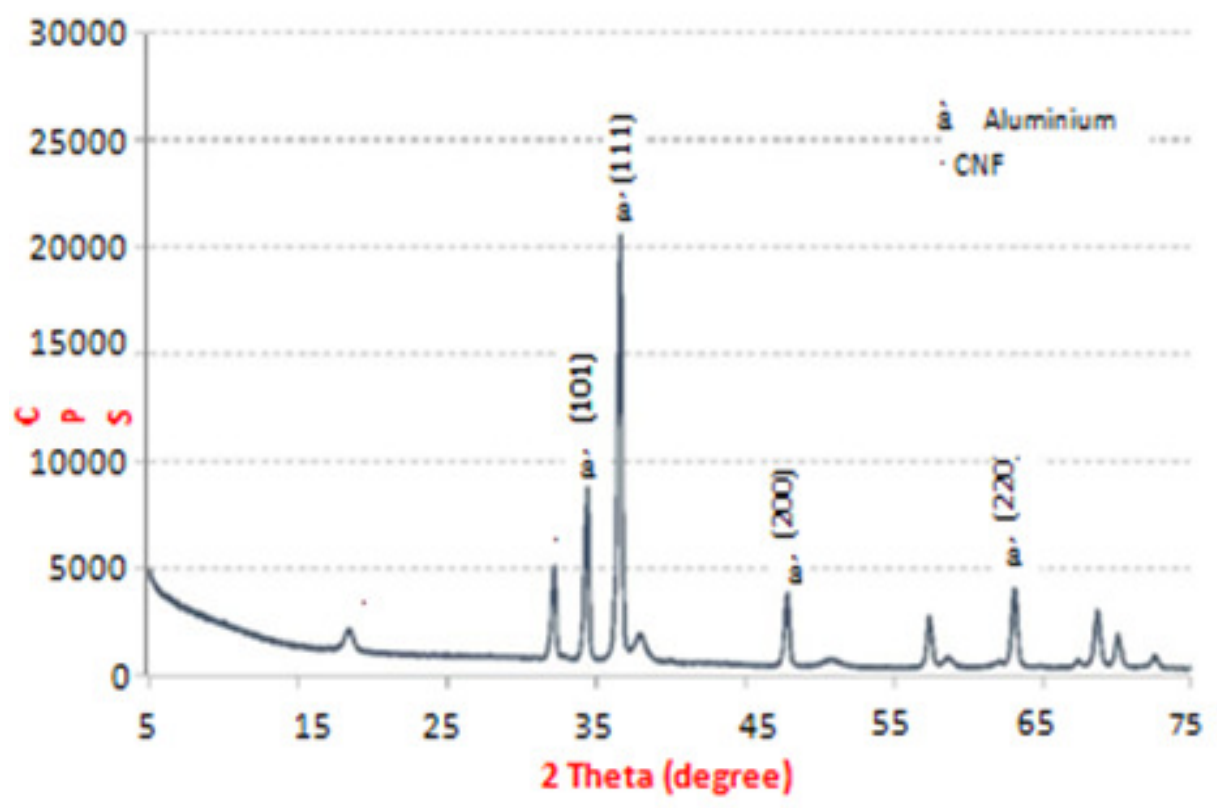

Figure5:XRD Scanning for Al/CNF powder after mixing

Fig. 5 shows the XRD patterns of $\mathrm{Al} / \mathrm{CNF}$ powder after mixing. It can be observed that the main peaks is corresponds to Aluminium crystals which present at $2 \boldsymbol{\theta}$ equal to 38, 46 and 63, in additional to the carbon fiber main peak at $2 \square=16.88^{\circ}$ corresponds to a spacing of $d=5.25 \mathrm{~A}^{\mathrm{o}}$. 
International Journal of Advances in Materials Science and Engineering (IJAMSE) Vol.7, No.2, April 2018

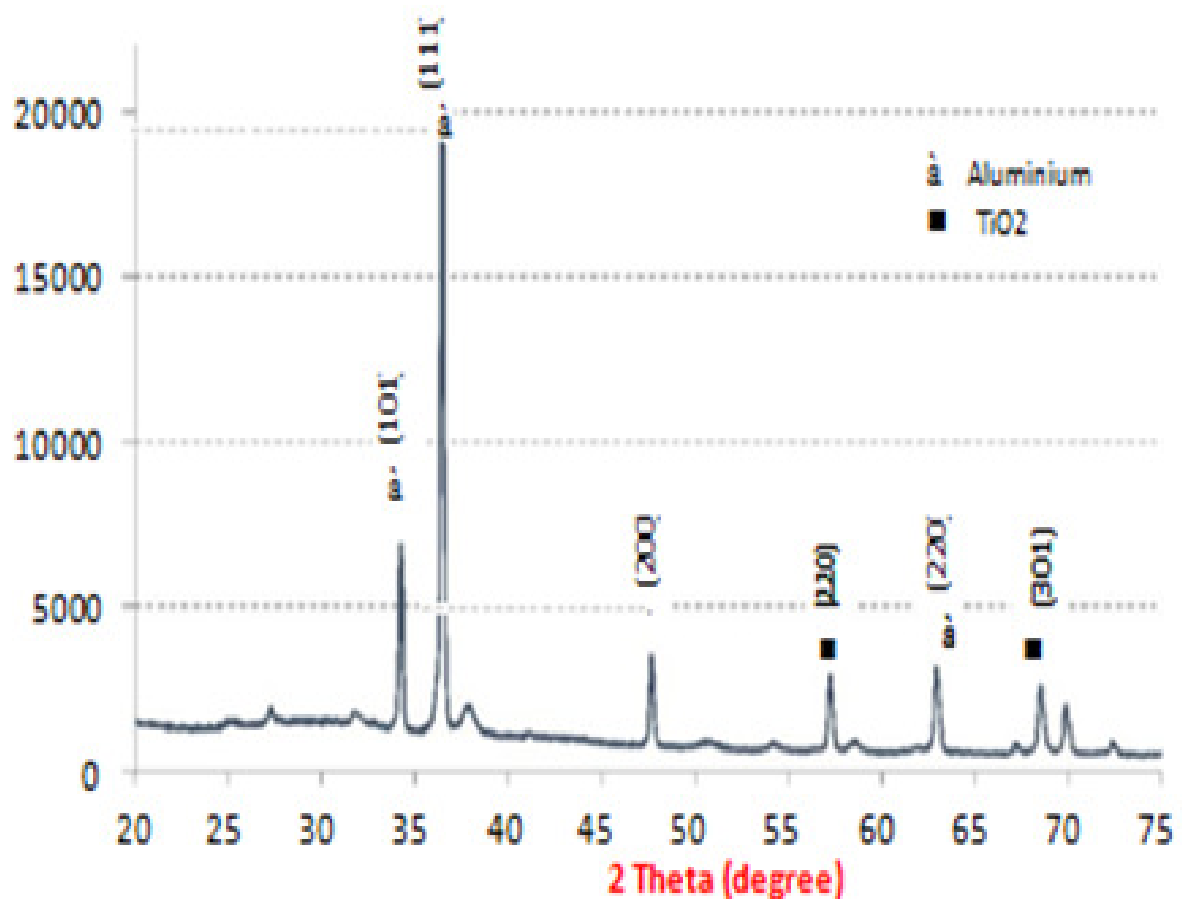

Figure6:XRD Scanning for $\mathrm{Al} / \mathrm{TiO}_{2}$ powder after mixing

Fig. 6 shows the XRD patterns of $\mathrm{Al} / \mathrm{TiO}_{2}$ powder after mixing. The results indicated that, the $\mathrm{XRD}$ configurations are similar to those found in $\mathrm{Al} / \mathrm{CNF}$ except the replacement of CNF by $\mathrm{TiO}_{2}$. The peaks of Aluminium which present at 20 equal to 38, 46 and 63, in additional to the $\mathrm{TiO}_{2}$ fiber main peaks at $2 \square=32.3^{\circ}$ and $57.16^{\circ}$

\subsection{DENSITY AND HARDNESS MEASUREMENTS}

Density and hardness results of the synthesized nanocomposites measured for different three samples from each composition are shown in Table 3 . From the density measurements, marginal increase in the density values by increasing the reinforcements percentage was observed and thereby ensuring the suitability of the fabricated $\mathrm{Al}$ composites for weight critical applications. A maximum hardness of $\sim 100.72$ was observed in the case of $\mathrm{Al}$ and 10\% $\mathrm{TiO} 2$ nanocomposites. From the results of the density and hardness measurements, it is observed that by utilizing the fabrication methodology, near dense Al based materials can be fabricated. 
International Journal of Advances in Materials Science and Engineering (IJAMSE) Vol.7, No.2, April 2018

Table 3:Density and hardness measurements of Al nano composites.

\begin{tabular}{|c|c|c|c|c|c|c|}
\hline \multirow{2}{*}{$\begin{array}{c}S I \\
N o .\end{array}$} & \multirow[b]{2}{*}{ Material } & \multicolumn{2}{|c|}{ Reinforcement } & \multicolumn{2}{|c|}{ Density measurements } & \multirow{2}{*}{$\begin{array}{c}\text { Hardness } \\
\text { measurem ents } \\
\text { HV } \\
\end{array}$} \\
\hline & & Morphology & $(W t \%)$ & $\begin{array}{l}\text { Density } \\
(\mathrm{gm} / \mathrm{Cm} 3)\end{array}$ & $\begin{array}{l}\text { Theoretical } \\
\text { Density }\end{array}$ & \\
\hline 1 & \multicolumn{2}{|c|}{ Pure Al } & $0 \%$ & 2.67 & 2.70 & 76 \\
\hline 2 & \multirow{4}{*}{ Al } & \multirow{4}{*}{ TiO2 } & $1 \%$ & 2.66 & 2.71 & 91.03 \\
\hline 3 & & & $3 \%$ & 2.62 & 2.73 & 95.67 \\
\hline 4 & & & $5 \%$ & 2.64 & 2.75 & 97.68 \\
\hline 5 & & & $10 \%$ & 2.62 & 2.80 & 100.72 \\
\hline 6 & \multirow{4}{*}{ Al } & \multirow{4}{*}{ CNF } & $1 \%$ & 2.54 & 2.69 & 77.95 \\
\hline 7 & & & $3 \%$ & 2.48 & 2.68 & 76.08 \\
\hline 8 & & & $5 \%$ & 2.36 & 2.66 & 74.92 \\
\hline 9 & & & $10 \%$ & 2.29 & 2.63 & 74.13 \\
\hline
\end{tabular}

\subsection{COMPRESSION PROPERTIES}

It can be seen that from Figs. 7 and 8, increasing the percent of ceramic nanofiber content, the ultimate compressive strength increased to $415 \mathrm{MPa}$ at $5 \% \mathrm{TiO} 2$. The increase of fracture strength might be related to the good interfacial bonding between the ceramic NFs clusters and Al matrix. While the opposite happened by increasing CNFs content to the Al matrix. The decrease of strength maybe related to the poor interfacial bonding between the CNFs clusters and Al matrix, which weakened the crack bridging effect of the CNFs consider

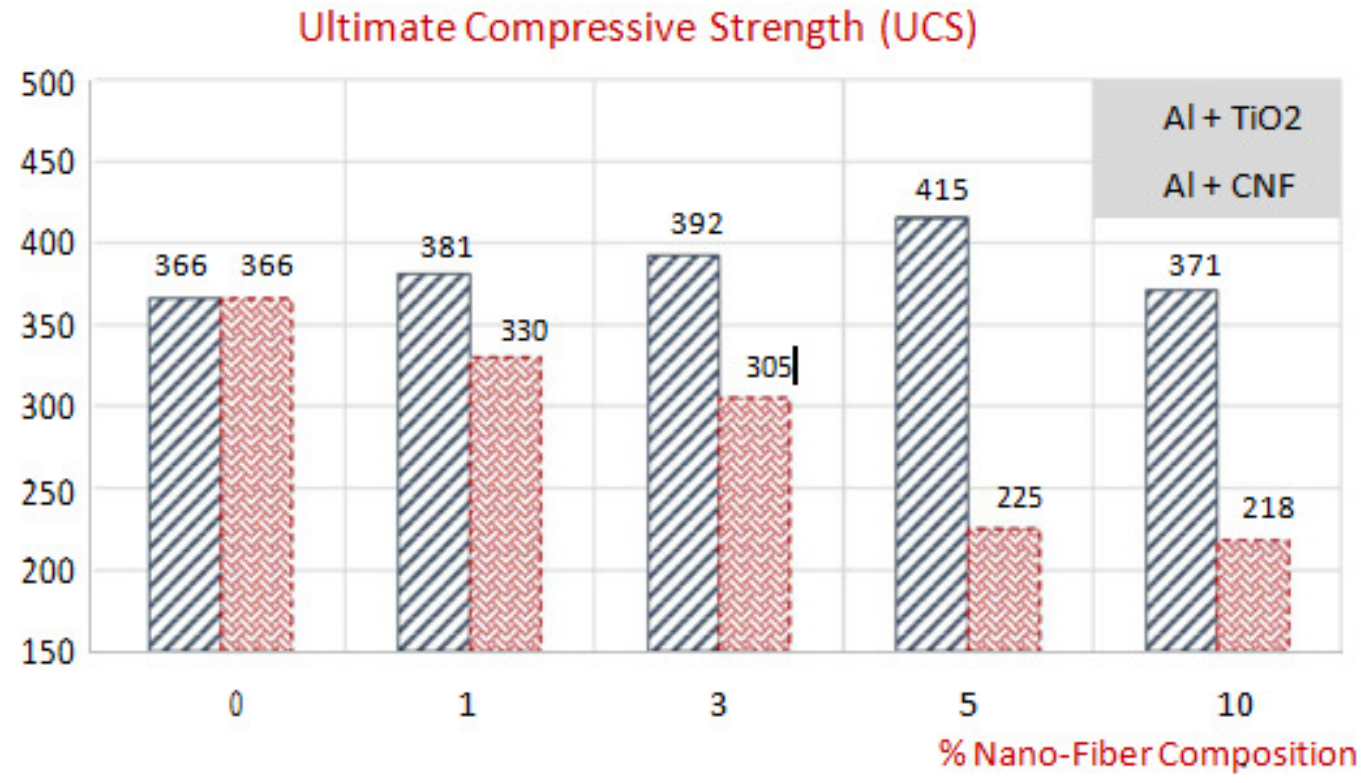

Figure 7: Ultimate compressive stress for $\mathrm{Al} / \mathrm{TiO}_{2}$ and $\mathrm{Al} / \mathrm{CNF}$ compared by pure Aluminium 
International Journal of Advances in Materials Science and Engineering (IJAMSE) Vol.7, No.2, April 2018

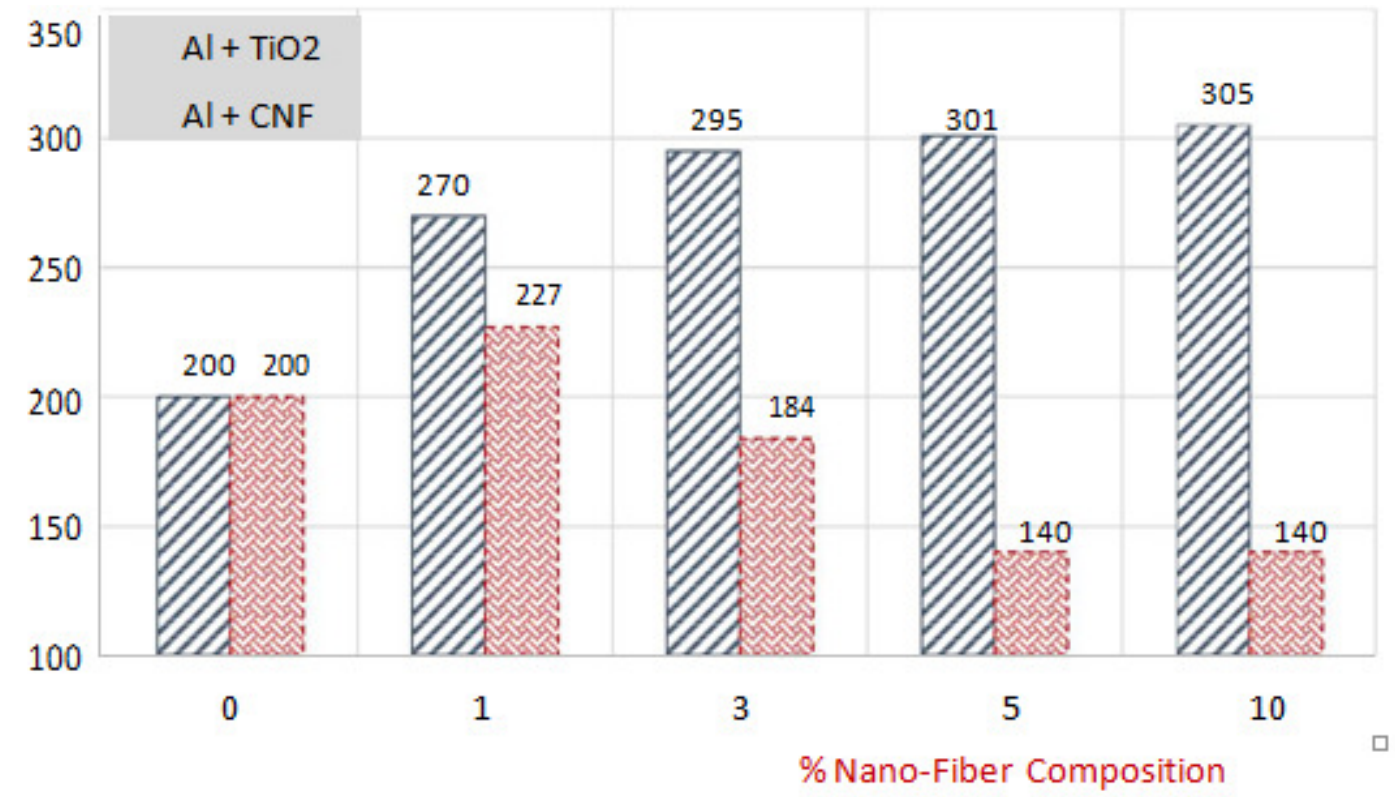

Figure 8: Yield compressive strength for $\mathrm{Al} / \mathrm{TiO}_{2}$ and $\mathrm{Al} / \mathrm{CNF}$ compared by pure Aluminium

Fracture surfaces of $\mathrm{Al}$ composites with $\mathrm{TiO}_{2}$ and $\mathrm{CNF}$ contents are shown in Fig.

9 (a) and (b). The addition of nanofibers help in improving the solidification

10 process. As shown, the distribution and orientation of nanofiber in the aluminium composites is homogeneous. There is no change observed during the synthesized nanocomposites process according to the XRD results Figs. 10 and 11
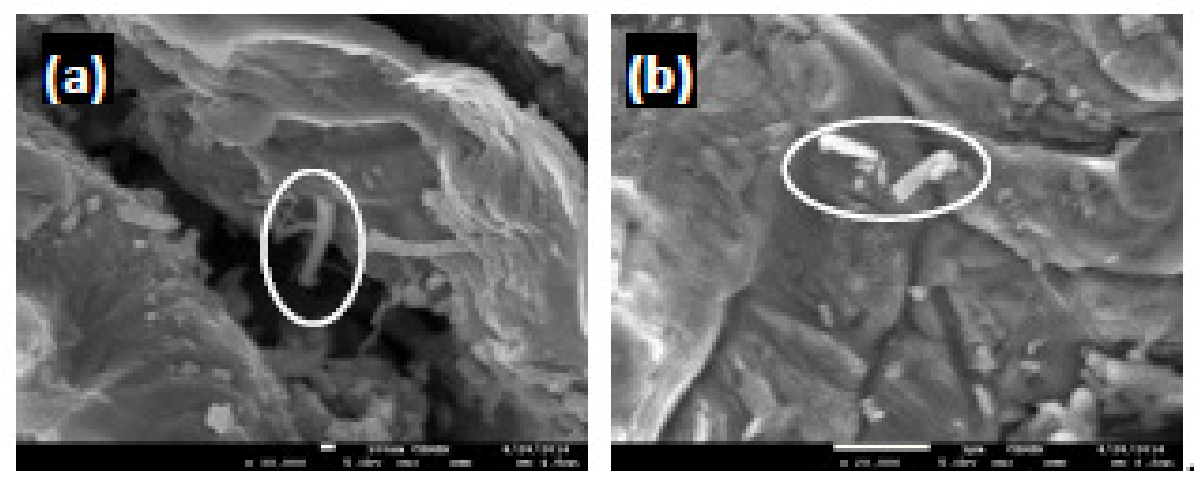

Figure 9: SEM images for the fracture surface after compression test (a) $\mathrm{Al} / \mathrm{TiO} 2$ (b) $\mathrm{Al} / \mathrm{CNF}$ 
International Journal of Advances in Materials Science and Engineering (IJAMSE) Vol.7, No.2, April 2018

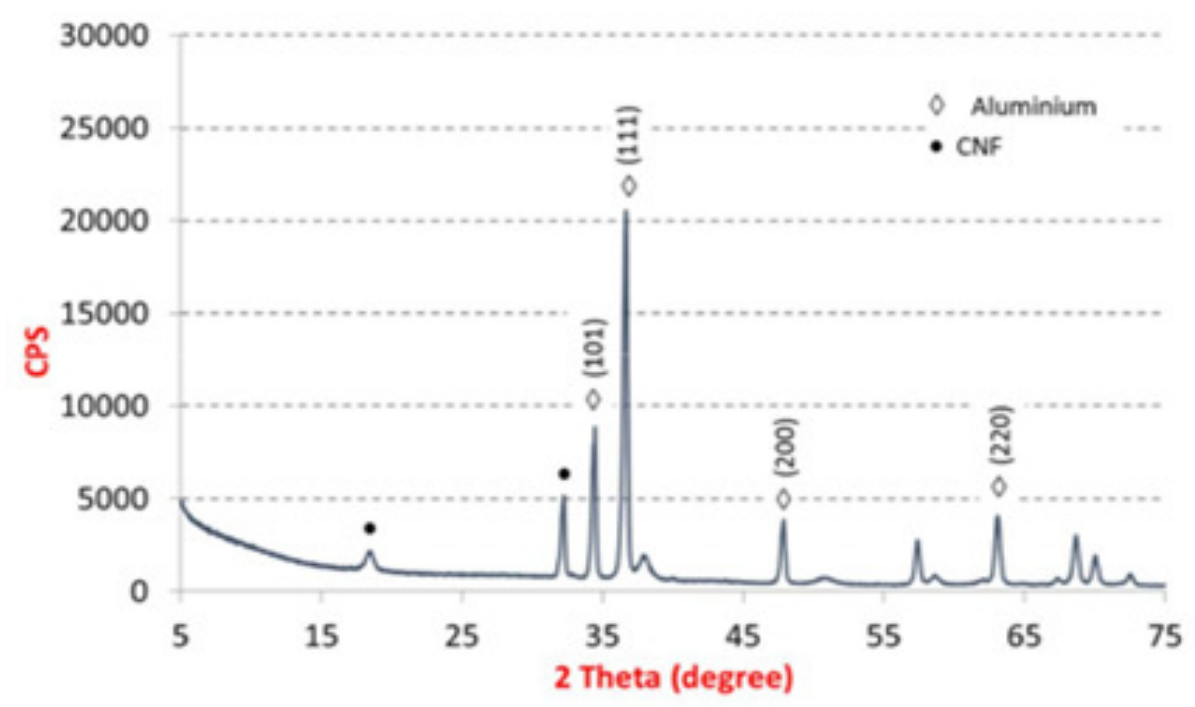

Figure10:XRD Scanning for Al/CNF synthesized nano composites

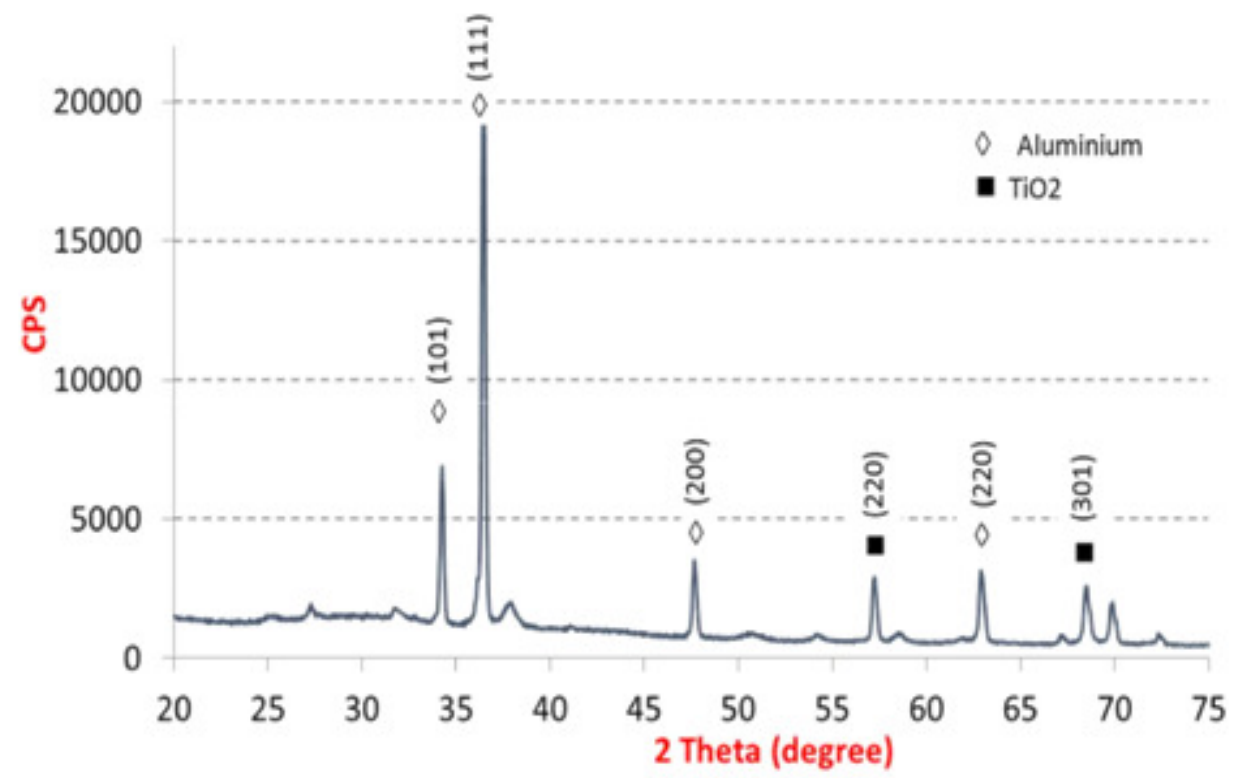

Figure 11: XRD Scanning for $\mathrm{Al} / \mathrm{TiO}_{2}$ synthesized nanocomposites. 
International Journal of Advances in Materials Science and Engineering (IJAMSE) Vol.7, No.2, April 2018

\section{CONCLUSION}

Carbon nanofibers and ceramic nanofibers (Titanium Oxide) were successfully synthesized and utilized as reinforcement for light metal matrices. Composites were successfully prepared using High Frequency Induction Heat Sintering furnace (HFIHS). The results can be concluded as follows:

1.The addition of ceramic nanofibers into light metal matrices clearly showed improvement in the reinforcement is mainly due to the good interfacial adhesion between fibers and metals matrix, which leads to improvement of the mechanical properties of the composite, high hardness.

2.Furthermore, the mechanical properties of the reinforced composites can be modulated by adjusting the volume fraction of nanofibers.

3.Adding CNFs to the light metal matrices leads to a decrease in strength especially at high percentage (more than $1 \%$ ).

4.Compressive properties results show that there are simultaneous improvements in hardness, yield and ultimate compressive strengths (UCS) up to $10 \mathrm{wt} . \% \mathrm{TiO}_{2} \mathrm{NF}$. But while using CNFs as a reinforcement, an increase in the yield strength and hardness were observed till $1.0 \mathrm{wt} . \%$ of $\mathrm{CNFs}$ in $\mathrm{Al} / \mathrm{Mg}$, then, more addition of CNFs to the metal matrix will lead to poor yield, UCS and hardness.

\section{REFERENCE}

[1] N. Chawla, K.K. Chawla, Metal Matrix Composites, Springer, New York, 2013.

[2] S. Rawal, Metal-matrix composites for space applications, JOM 53 (4) (2001) 14- 17.

[3] B. Ratna Sunil, Developing Surface Metal Matrix Composites: A Comparative Survey, International Journal of Advances in Materials Science and Engineering (IJAMSE) Vol.4, No.3, July 2015.

[4] Wei-Hsio Chen, Hao-Tung Lin, Jianmin Chen, Pramoda K. Nayak, Alex C. Lee, Horng-Hwa Lu, Jow-Lay Huang, Microstructure and wear behavior of spark plasma sintering sintered Al2O3/WCbased composite, International Journal of Refractory Metals and Hard Materials, 54 (2016) 279-283.

[5] I. Tsunemichi, M. JianFu, D. Shangli, S. Ichinori, S. Naobumi, L. Gilles, High strain rate superplasticity of TiC particulate reinforced 2014 aluminum alloy composites, Materials Science and Engineering A 364 (2004) 281-286.

[6] I. Kerti, Production of TiC reinforced-aluminum composites with the addition of elemental carbon, Materials Letters 59 (2005) 3795-3800.

[7] M K Surappa, Aluminium matrix composites: Challenges and Opportunities. Sādhanā Vol. 28, Parts 1 \& 2, February/April 2003, pp. 319-334.

[8] N. Hansen, Strengthening of aluminium by a three-dimensional network of aluminium-oxide particles, Acta Metall. 17 (1969) 637-642. 
International Journal of Advances in Materials Science and Engineering (IJAMSE) Vol.7, No.2, April 2018

[9] Zhang DL, Koch CC, Scattergood RO. The role of new particle surfaces in synthesiszing bulk nanostructured metallic materials by powder metallurgy. Mater Sci Eng A 2009;516:270-5.

[10] Montazeri A, Javadpour J, Khavandi A, Tcharkhtchi A, Mohajeri A. Mechanical properties of multiwalled carbon nanotube/epoxy composites. Mater Des 2010;31:4202-8

[11] Bhaduri A, Gopinathan V, Ramakrishnan P, Miodownik AP. Processing and properties of SiC particulate reinforced $\mathrm{Al}-6.2 \mathrm{Zn}-2.5 \mathrm{Mg}-1.7 \mathrm{Cu}$ alloy (7010) matrix composites prepared by mechanical alloying. Mater Sci Eng A 1996;221:94-101.

[12] Sub ZQ, Zhang D, Li GB. Evaluation of dry sliding wear behavior of silicon particles reinforced aluminum matrix composites. Mater Des 2005;26:454-8.

[13] Slipenyuk A, Kuprin V, Milman Y, Goncharuk V, Eckert J. Properties of P/M processed particle reinforced metal matrix composites specified by reinforcement concentration and matrix-toreinforcement particle size ratio. Acta Mater 2006;54:157-66.

[14] Dudina DV, Georgarakis K, Li Y, Aljerf M, LeMoulec A, Yavari AR, et al. A magnesium alloy matrix composite reinforced with metallic glass. Compos Sci Technol 2009;69:2734-6.

[15] Lee MH, Kim JH, Park JS, Kim JC, Kim WT, Kim DH. Fabrication of Ni-Nb- Ta metallic glass reinforced Al-based alloy matrix composites by infiltration casting process. Scripta Mater 2004;50:1367-71.

[16] Scudino S, Surreddi KB, Sager S, et al. Production and mechanical properties of metallic glassreinforced Al-based metal matrix composites. J Mater Sci 2008;43:4518-26.

[17] Khalil, K.A.; Sherif, E.-S.M.; Nabawy, A.M.; Abdo, H.S.; Marzouk, W.W.; Alharbi, H.F. Titanium Carbide Nanofibers-Reinforced Aluminum Compacts, a New Strategy to Enhance Mechanical Properties. Materials 2016, 9, 399. 